\title{
Rekayasa Alat Pembuat Disk Runner Dengan Sistim Jig Dan Fixture
}

\author{
Engineering Tool For Making Runner Disks With Jig And Fixture System
}

\author{
Alfian, Fardinal, Islamiati \& Andri
}

Jurusan Teknik Mesin Politeknik Negeri Padang Kampus Limau Manis Padang

Telp.0751-72590 Fax.0751-72576 Email: alfian_sofjan@yahoo.co.id

\begin{abstract}
Electrical energy at this time is needed in daily life so that the demand for power from the community is so large. PLN in this case as a provider of electric current is very overwhelmed to meet customer demand. For this reason, alternative energy producers called renewable energy are sought, one of which is a micro hydro plant. In West Sumatra alone, PLTMH has considerable potential to reach 500 MW (Source: PLN West Sumatra Regional Research and Development), so that West Sumatra itself has been designated a green energy barn by the Ministry of Energy and Mineral Resources (Source: Ministry of Energy and Mineral Resources). This is a promising prospect to be developed so that PLTMH equipment can be made with the mastery of appropriate technology.

Based on the survey that has been done generally making microhydro turbines is still doing manual work with simple production equipment and very low production volume. The delay in making this generator is in the runner which has a disk component as a holder where the blade will produce rotation. Part made has a specific contour shape and repetitive work. Making disk runners through six workmanship sequences using different CAD applications, tools and places.

Jig and Fixture is a technological tool that is suitable for manufacturing micro hydro turbine disk runners where the material holder is on the dividing plate while the torch weld cutter is hung on the guide for the cutting process. These assistive tools designed can eliminate the work process. This mobile device can cut circles with a diameter of $200 \mathrm{~mm}-300 \mathrm{~mm}$, a blade of as many as 28 pieces with the same distance, shape profile and accuracy and meet the ergonomic aspects for the operator.
\end{abstract}

Keywords : jig, fixture, mikrohidro, runner, disk

\section{PENDAHULUAN}

Jenis turbin air yang biasa digunakan untuk PLTMH yang dipakai di Indonesia adalah jenis turbin aliran silang (cross flow) seperti terlihat pada Gambar 1. Turbin ini dikenal juga sebagai turbin Michell-Banki yang menjadi penemu turbin jenis ini. Turbin ini mempunyai runner yang berbentuk seperti drum yang terdiri dari 2 atau lebih disc runner yang masingmasingnya dihubungkan oleh susunan sudu yang berbentuk lengkung [9]. Dalam pengoperasian turbin mikrohidro ini, sebuah nosel empat persegi mengarahkan pancaran air (jet) ke sepanjang runner. Pancaran air tersebut mendorong sudu dan memindahkan sebagian besar energi kinetiknya ke turbin.

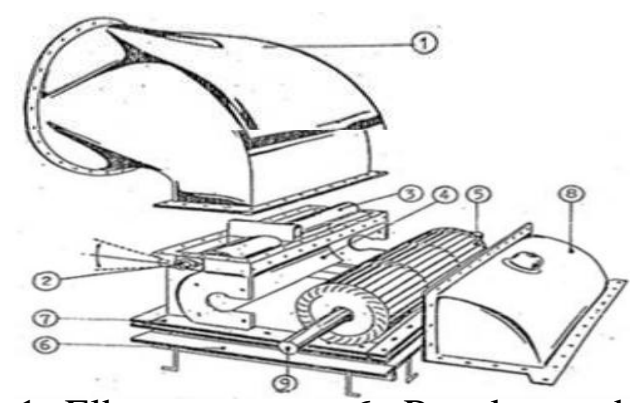

1. Elbow 6. Rangka pondasi

2. Poros katup

7. Rumah turbin

3. Katup

4. Nosel

8. Tutup turbin

5. Runner

Gambar1. susun turbin mikrohidro

\section{Analisis Proses Pembuatan Turbin}

Fabrikasi turbin mikrohidro dengan tipe turbin aliran silang (cross flow) melibatkan pembuatan masing-masing komponen seperti terlihat pada Gambar 1 
dan diakhiri dengan proses parakitan. Bagian yang terpenting disini adalah pembuatan runner turbin seperti diperlihatkan pada Gambar 2. Runner atau pemutar turbin aliran silang ini terdiri dari disc runner, sudu dan poros. Disc runner yang berfungsi sebagai dudukan sudu turbin yang mempunyai kelengkungan serta sudut kemiringan tertentu guna mendapatkan efisiensi turbin yang tinggi serta menghasilkan luaran daya listrik yang besar.

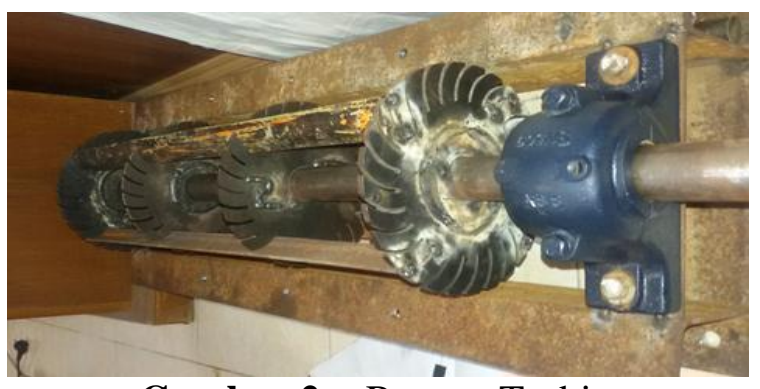

Gambar 2. : Runner Turbin

Pembuatan disc runner turbin air jenis aliran silang pada beberapa tempat di Jawa telah memanfaatkan mesin-mesin canggih, dalam hal ini CNC Wire Cutting untuk menghasilkan produk yang berkualitas dan teliti. Pengerjaan disc runner dengan peralatan CNC Wire Cutting dibutuhkan modal yang besar karena, harga mesin CNC yang mahal dan belum sesuai dengan skala ekonomis untuk bengkel-bengkel dengan skala konvensional serta, mendapatkan pekerjaan dengan berdasarkan job shop bukan order yang berkelanjutan. Bengkelbengkel yang disurvei menunjukkan pengerjaan masih sangat manual. Sehingga dalam penelitian ini perlu diimplementasikan suatu teknologi yang cocok dengan mempergunakan sistim jig and fixture dalam proses pembuatan turbin mikrohidro khusus untuk bagian komponen runner turbin.

Tujuan dari penelitian ini adalah:

a. Merekayasa dengan merancang dan membuat alat bantu jig and fixture untuk pembuatan disk runner dengan ukuran $300 \mathrm{~mm}$.

b. Melakukan pengujian terhadap alat bantu jig and fixture pada pembuatan disk runner turbin untuk mengetahui kecepatan waktu, keterulangan pekerjaan, ketelitian dan ergonomik.

\section{Urgensi (Keutamaan) Penelitian}

Pembuatan alat bantu jig and fixture perlu dilakukan untuk membuat disk runner turbin mikrohidro. Proses pembuatan disk runner yang sangat kompleks dan mempunyai keterulangan pekerjaan sehingga, proses produksinya melalui banyak perlakuan seperti membuat mal, penandaaan, pelubangan, penggoresan dan pemotongan. Agar didapatkan disk runner dengan karakteristik bentuk fisik dan mekanisnya sesuai dengan standar sebuah turbin mikrohidro untuk dapat dilakukan pembuatannya dalam bentuk komersil.

Urgensi (keutamaan) dari kegiatan ini adalah efisiensi proses pembuatan disk runner dengan menggunakan alat bantu jig and fixture dibandingkan dengan secara manual yang sudah dilakukan. Teknologi yang digunakan pada kegiatan ini adalah proses mencekam benda kerja pada bagian clamping yang disebut dengan fixture, proses pembagian segmen dudukan sudu turbin dengan menggunakan kepala pembagi yang akan membagi dudukan sudu pada disk runner sama besar dan proses pemotongan yang menggunakan torch weld dengan hasil potongan radius dengan sama besar yang disebut dengan jig. Prinsip dasar dari Alat bantu jig and fixture ini adalah melakukan pencekaman terhadap material disk runner yang berbentuk prismatik lalu, dipotong menjadi silindris dengan mengunakan torch weld sebagai pemotong dan kepala pembagi sebagai pemutar akan menyentuhkan material dengan busur api dari torch weld sampai disekeliling bahan sehingga, terbentuk silindris dengan diameter $300 \mathrm{~mm}$. Bahan disk runner yang sudah berbentuk bulat kemudian dilakukan pemotongan untuk tempat dudukan sudu yang berjumlah 28 segmen sama besar dan mempunyai radius tertentu dengan, memanfaatkan kepala pembagi dalam membagi segmen sama besar dan pillar sebagai pengatur gerakan 
orch weld dalam pemotongan radius dudukan sudu.

\section{Survei Pembuatan Disc Runner}

Hasil survei proses pembuatan cakram putar (disc runner) turbin mikrohidro yang dilakukan pada bengkel adalah dengan urutan sebagai berikut:

a. Pembuatan gambar disc runner dengan software CAD skala 1:1 dan ditempelkan pada material mild steel untuk dijadikan template disc runner (Gambar 3)

b. Proses penandaan dengan penitik besi dilanjutkan dengan penandaan dengan cara mengurdi sebanyak 28 lubang dengan diameter $8 \mathrm{~mm}$ (Gambar 3)

c. Proses perataan pada permukaan material pelat dengan palu besi $(5 \mathrm{~kg})$ yang dipukulkan ke permukaan material sampai permukaannya rata.
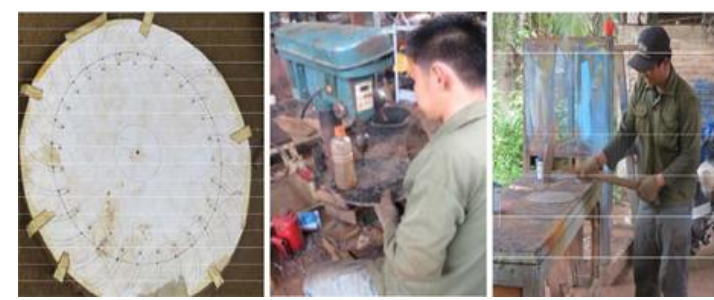

Gambar 3. penandaan dan meratakan pembuatan disc runner

d. Proses penandaan tempat sudu runner dengan bantuan penitik dan jangka besi (untuk penandaan jari-jari kelengkungan sudu (Gambar 3)

e. Proses selanjutnya adalah pemotongan material bakal disc runner dengan mempergunakan las gas asetilene (Gambar 4).
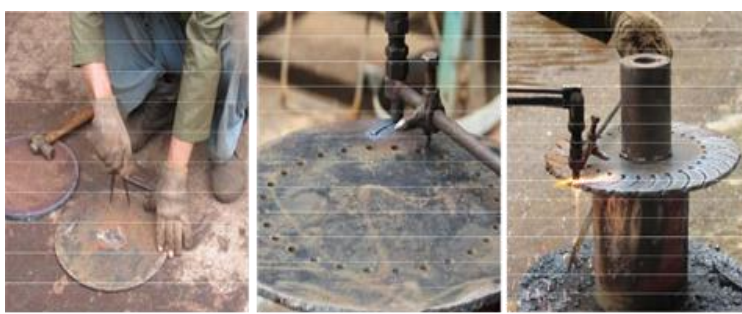

Gambar 4. Penandaan dan pemotongan disc runner

Konsep Desain yang Ditawarkan
Konsep disain teknologi fabrikasi yang dipakai pada perancangan alat bantu untuk pembuatan disk runner turbin mikrohidro ini adalah:

- Mereduksi waktu pengerjaan

- Menjamin ketelitian

- Menjamin keterulangan (repeatability)

- Mengintegrasikan aspek ergonomi

Perkakas bantu pegang dan pengarah (jig and fixture) yang dibuat seharusnya mempersingkat atau mereduksi waktu pengerjaan disc runner karena dalam satu perkakas bantu yang dirancang ini menggabungkan beberapa elemen pekerjaan (operasi) yang sebelumnya dilakukan dengan cara manual dan terpisah. Langkah operasi ini seperti pembuatan template disc runner dengan gambar CAD, penandaan (marking) pada material pelat dengan penitik, penandaan jangka dan penggurdian dapat diintegrasikan dalam suatu langkah proses yang terintegrasi dengan perkakas bantu yang dibuat.

Solusi yang ditawarkan juga berkaitan dengan ketelitian dan keterulangan (repeatability) dari pengerjaan. Perkakas bantu nantinya akan dilengkapi dengan kepala pembagi yang berfungsi untuk membagi dudukkan sudu benda kerja yang akan di potong sebanyak jumlah sudu turbin yang diingini secara teliti. Demikian juga dengan bagian jig yang mengarahkan torch weld dengan kelengkungan yang benar dan berulang untuk profil sudu-sudu lainnya. Dengan demikian proses pembuatan dapat menjamin juga sifat mampu ulang (repeatability).

Solusi lain yang diberikan adalah yang berkaitan dengan human factor yaitu aspek ergonomi dalam pekerjaan. Desain perkakas bantu yang akan dibuat telah memperhatikan aspek ergonomi (kesesuaian dengan antropometri manusia Indonesia) dan analisa perancangan kerja (APK). Dengan hal ini diharapkan kenyamanan dan keselamatan kerja bagi operator menjadi lebih terjamin.

Material yang digunakan untuk pembuatan perkakas bantu adalah material 
yang mudah ditemukan di pasaran agar lebih murah (low-cost). Diharapkan biaya pembuatan jig and fixture ini juga lebih murah sehingga menghasilkan ongkos tetap (fixed cost) yang juga rendah, sehingga cocok dipakai oleh bengkel skala industri mikro dan UMKM. Dengan ini diharapkan titik impas (break-even point) dapat dengan jumlah produksi yang masih rendah.

\section{Rancangan Beberapa Prototipe}

Rancangan perkakas bantu terbagi atas dua bagian. Yang pertama adalah perkakas yang memegang (to hold or to clamp), mengalokasikan (to alocate) dan sekaligus memutar benda kerja yang akan difabrikasi, dalam hal ini disebut saja perkakas bantu pegang (fixture). Yang kedua adalah perkakas yang mengarahkan/ menuntun torch las gas asetilen pada proses memotong profil sudu turbin. Yang disebut terakhir ini berfungsi sebagai suatu jig atau menuntun jalannya perkakas potong.

Perkakas bantu pegang dan pengarah (jig and fixture) dirancang untuk pembuatan disc runner berdiameter cakram maksimum $300 \mathrm{~mm}$, jumlah dudukan sudu hingga 28 lengkungan. Perkakas bantu ini juga dapat dipergunakan untuk pemotongan material plat (lembaran) dalam bentuk prismatik (persegi) menjadi silindris (bulat) dengan besar dimensi material sama dengan besar material disc runner. Torch las gas asetilen merupakan alat pemotong yang dipakai untuk pembuatan lengkungan disc runner. design perkakas bantu pegang dan pengarah untuk pembuatan disc runner turbin mikrohidro yang dibuat ini (Gambar 2.3) terdiri dari beberapa komponen utama sebagai berikut:

- Meja kerja

- Kepala pembagi

- Clamping benda kerja

- Pengarah torch las (Pillar) dan mekanismenya

Meja kerja adalah tempat dudukan dari perkakas bantu yang dibuat sehingga harus dibuat kuat dan kaku. Meja kerja berbentuk segi empat dengan dimensi $320 \mathrm{x}$ 500 × $750 \mathrm{~mm}$. Tinggi kerja disesuaikan dengan ukuran tubuh orang Indonesia dan tipe pekerjaan yang membutuhkan keluwesan gerak dan operator kerja untuk pria. Kepala pembagi dirancang dengan material pelat mild steel dan berfungsi melakukan pembagian disc runner dengan sudut pembagi yang ditentukan. Pemutar berhubungan dengan poros dan sebuah gear box yang poros masuknya horizontal dan poros keluarnya vertikal. Poros keluar ini akan memutar piring pembagi yang berhubungan dengan pemegang benda kerja. Clamping benda kerja disebut juga dengan fixture, terdiri dari landasan dan pencekam. Kedua komponen tersebut digabung dalam satu poros bertingkat serta berulir diujungnya untuk dipasangkan mur. Pengarah torch las (Pillar) terdiri dari bagian pemegang torch dan mekanisme pengarah berbentuk lengan kinematik. Pengarah ini harus rigid supaya pada waktu pemotongan dengan torch las asitilene maka profil lengkungan sudu yang dihasilkan cukup teliti.

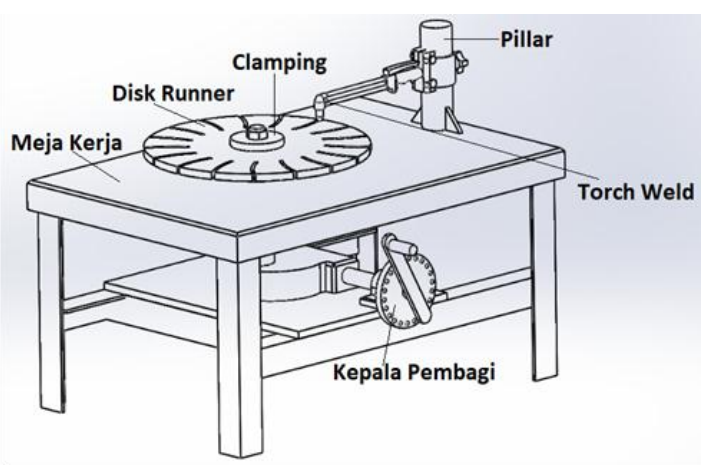

Gambar 5. Rancangan alat jig and fixture untuk pembuatan disc runner turbin

Perkakas bantu ini diharapkan memberikan solusi bagi persoalan dalam pembuatan fabrikasi turbin mikrohidro. Beberapa indikator perbaikan yang ingin dicapai dengan penggunaan perkakas bantu adalah sebagai berikut:

- Keterulangan (repeatability) dari profil sudu yang lebih baik sehingga dapat mengurangi dengan cukup signifikan pengerjaan tambahan 
- Ketelitian dimensional dari produk hasil

- Waktu pengerjaan yang dapat dikurangi karena perkakas bantu dapat mereduksi atau bahkan mengeliminir beberapa pekerjaan tambahan, penandaan (marking), perbaikan (reworks) dan penyetelan setiap langkah proses

- Ergonomi untuk pekerja Indonesia

\section{METODOLOGI}

\section{Penentuan Permasalahan}

Berdasarkan analisa situasi yang sudah dilakukan melalui survei pendahuluan ke Bengkel yang berlokasi di Padang dapat diidentifikasi dan dirumuskan permasalahan yang dihadapi dalam fabrikasi turbin air jenis cross flow (terutama bagian runner turbin) sebagai berikut :

1. Fabrikasi pembuatan turbin air aliran silang untuk PLTMH bersifat job order dan tergolong konvensional (manual) dan belum tersentuh aplikasi teknologi manufaktur yang bersifat medium-technology, sementara permintaan akan turbin mikrohidro diprediksi akan meningkat disebabkan dukungan dari pemerintah terutama dengan ditetapkannya Sumbar oleh Kementrian ESDM sebagai lumbung energi hijau.

2. Salah satu komponen yang terdapat pada runner turbin air yaitu disc runner merupakan komponen kunci yang pembuatannya cukup rumit. Dari pengamatan di mitra, diketahui cukup banyak persiapan kerja yang terjadi di luar fabrikasi itu sendiri seperti pembuatan gambar disc runner dengan program aplikasi CAD untuk template proses pembuatan. Persiapan kerja juga dilakukan untuk penandaan (marking) dengan penitik, jangka maupun mesin gurdi untuk menghasilkan profil sudu yang benar. Demikian juga setelah dilakukan proses pemotongan dengan gas asetilene, maka perlu dilakukan pengerjaan tambahan yang bersifat perbaikan (reworks) agar profil yang dihasilkan sesuai dengan sudunya. Akibat dari hal ini maka waktu pengerjaan non-produktif (gambar CAD, marking, pekerjaan perbaikan) menjadi lebih dominan sehingga secara kumulatif akan menghasilkan waktu total pengerjaan yang lama.

3. Disc runner untuk turbin mikrohidro ini dengan jumlah sudu yang cukup banyak membutuhkan kesamaan bentuk profil dan ukuran. Maka konsekuensinya adalah keterulangan (repeatability) pengerjaan menjadi sangat penting. Dengan cara manual yang dilakukan mitra sekarang ini maka hal ini menjadi permasalahan (keterulangan hasil masih rendah). Sehingga perlu dicari jalan keluarnya dengan membuat suatu perkakas bantu pengarah (jig) agar proses pemotongan sesuai dengan profilnya dan mampu ulang.

4. Ketelitian produk hasil juga sangat penting dan menjadi masalah mitra. Hal ini disebabkan karena banyak komponen-komponen yang berpasangan sehingga diperlukan toleransi dimensi. Dengan pengerjaan manual, ketelitian yang berkaitan dengan toleransi ini hanya dapat dicapai apabila dilakukan pengulangan pekerjaan, dimana dengan perkakas bantu hal ini dapat lebih dikurangi.

5. Selain itu beberapa operator kerja yang mengeluhkan tentang posisi dan postur kerja yang kurang ergonomis. Diharapkan hal ini dapat diatasi dengan rancangan perkakas bantu yang mengakomodir ukuran dan postur tubuh yang ergonomis dalam bekerja.

\section{Solusi yang ditawarkan}

Dari permasalahan di atas akan dibuat sebuah perkakas bantu pegang dan pengarah (jig \& fixture) sebagai suatu 
bentuk teknologi tepat guna pada fabrikasi komponen turbin mikrohidro di bengkel. Hal ini dipandang cocok karena tipe produksi masih bersifat job order dengan jumlah pesanan yang masih sangat rendah dan sporadis, dimana pemakaian mesin produksi yang maju belum dimungkinkan dari faktor skala ekonomis.

Perkakas bantu pegang dan pengarah (jig and fixture) yang akan dibuat akan mempersingkat waktu pengerjaan disc runner karena dalam satu perkakas bantu yang dirancang ini sudah menggabungkan beberapa elemen pekerjaan yang sebelumnya dilakukan dengan cara manual. Hal ini karena beberapa langkah proses sebelumnya seperti pembuatan template disc runner dengan gambar CAD, penandaan (marking) pada material pelat dengan penitik, penandaan jangka dan penggurdian dapat direduksi dalam suatu langkah proses yang terintegrasi dengan perkakas bantu yang dibuat.

Solusi yang ditawarkan ini juga berkaitan dengan ketelitian dan keterulangan (repeatability) dari pengerjaan. Perkakas bantu nantinya akan dilengkapi dengan kepala pembagi (dividing head) yang berfungsi untuk membagi dudukkan sudu yang akan di potong sebanyak jumlah sudu turbin yang diingini. Pembagian disc runner menjadi $n$ buah dudukkan sudu ditentukan oleh piringan yang ada pada kepala pembagi, yang berputar sesuai dengan jumlah dudukkan sudu. Ketelitian piringan dibuat sebaik mungkin supaya hasil pemotongan profil sudu pada disc runner menjadi teliti dan sama besar.

Selain itu, solusi lain yang diberikan adalah yang berkaitan dengan human factor yaitu aspek ergonomi dalam pekerjaan. Desain perkakas bantu yang akan dibuat telah memperhatikan aspek ergonomi dan analisa perancangan kerja (APK). Dengan hal ini diharapkan kenyamanan dan keselamatan kerja bagi operator pada mitra bengkel yang dipilih menjadi lebih terjamin.

\section{Rencana Kegiatan}

Rencana kegiatan yang akan dilakukan adalah sebagai berikut :

1) Melakukan survey lapangan ke lokasi fabrikasi pembuatan turbin air jenis cross flow. Dalam survey ini dilakukan peninjauan kembali proses pembuatan turbin air mikrohidro di mitra, mulai dari material awal sampai selesai (menjadi produk). Kemudian dilakukan wawancara dengan pemilik dan pekerja tentang permasalahan yang masih ada.

2) Mendiskusikan kembali permasalahan dalam pembuatan disc runner yang ada pada pemilik fabrikasi dan pekerja sehingga diperoleh masukkan yang lebih lengkap untuk dijadikan masukkan terhadap modifikasi rancangan perkakas bantu yang ada.

3) Melakukan diskusi dengan internal tim dan para teknisi. Luaran hasil ini nantinya adalah prototip perkakas bantu pegang dan pengarah (jig and fixture) untuk proses pembuatan disc runner turbin mikrohidro yang sudah memiliki engineering release untuk difabrikasi

4) Melakukan fabrikasi perkakas bantu. Proses fabrikasi dimulai dengan pembelian material dan komponen standar. Proses fabrikasi dilakukan oleh Mahasiswa D3 Teknik Mesin Politeknik Negeri Padang dengan supervisi dari tim peneliti dari Jurusan Teknik Mesin Politeknik Negeri Padang. Langkah selanjutnya adalah perakitan dan pengecatan.

5) Melakukan pengujian. Pengujian direncanakan pertama kali di Bengkel Produksi Teknik Mesin Politeknik Negeri Padang untuk melihat beberapa indikator yang ingin dicapai bersama-sama dengan mitra yaitu: keterulangan bentuk, ketelitian, pengurangan pekerjaan tambahan atau perbaikan, waktu pengerjaan yang lebih rendah serta kenyamanan pengoperasian (faktor ergonomi). 
6) Melakukan evaluasi dan monitoring produk yang dihasilkan dari pemakaian alat.

\section{HASIL DAN PEMBAHASAN}

\section{Hasil perhitungan alat}

Pada penelitian ini telah dirancang sebuah desain perkakas bantu jig dan fixture serta komponen-komponen yang digunakan untuk pembuatan disk runner. Perhitungan dilakukan dengan dukungan dari landasan teori dimana dihasilkan sebuah alat dengan kemampuan dapat mencekam benda kerja serta mempunyai pengarah untuk melakukan pemotong dengan menggunakan torch. Komponen utama dari hasil perhitungan antara lain dimensi rangka, pengarah, Pencekam benda kerja, dan piring pembagi. Hasil rancangan alat bantu dapat dilihat pada gambar berikut :

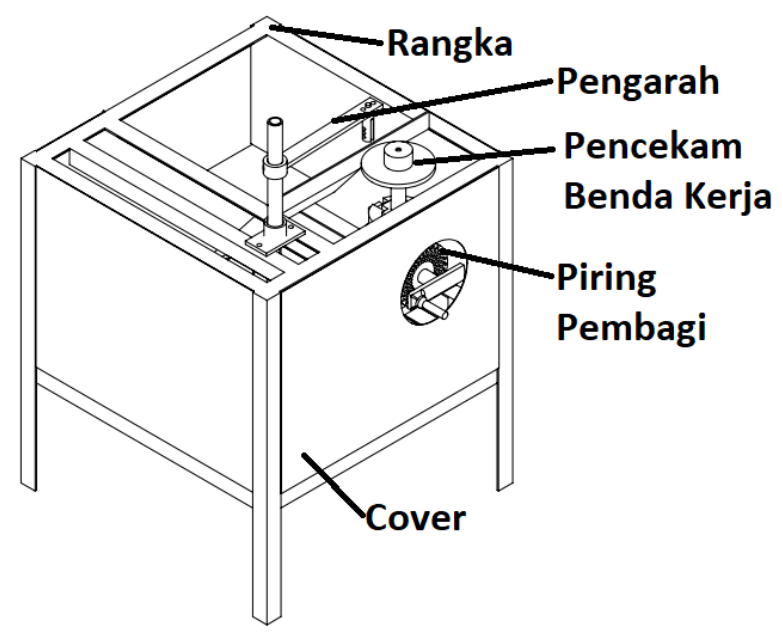

Gambar 6. Desain Alat Pembuatan Disk Runner

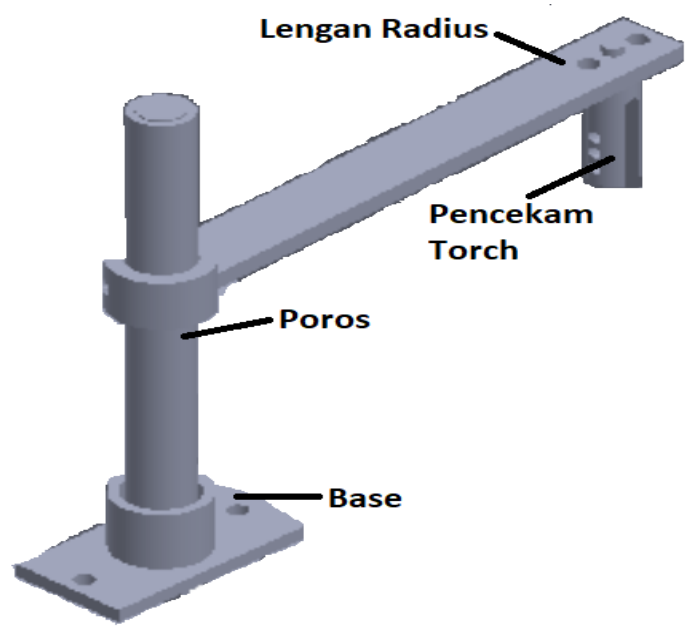

Gambar 7. Unit Jig

Desain pengarah (Jig) dibuat berdasarkan aspek pekerjaaan yang berulang untuk pembuatan sudu pada disk runner. Hasil dari perhitungan panjang lengan $245 \mathrm{~mm}$ sesuai dengan diameter bakal dari disk runner yang dibuat, pencekam torch dengan diameter $23 \mathrm{~mm}$ panjang $56.05 \mathrm{~mm}$ serta bush lift tiang dari kalkulasi menghasilkan diameter dalam 30 mm sedangkan diameter luarnya $48 \mathrm{~mm}$. Pada perhitungan tiang didapat hasil diameter 8.16, untuk memenuhi nilai estetika dan ketersediaan bahan dijadikan diameter $35 \mathrm{~mm}$.

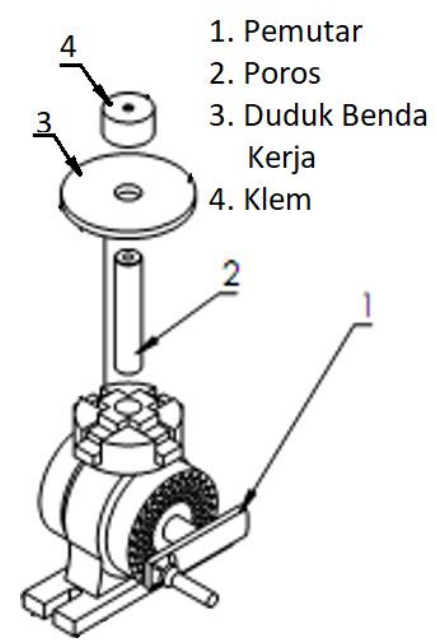

Gambar 8. Unit Fixture

Pada unit fixture terdapat empat komponen utama yang ketersediaannya ada yang 
dibuat dan ada dari bawaan alat. Komponen yang dibuat terlebih dahulu melalui perhitungan seperti poros dengan diameter $30 \mathrm{~mm}$, dudukan benda kerja berdiameter luar $150 \mathrm{~mm}$, diameter dalam $30 \mathrm{~mm}$ serta tebalnya $10 \mathrm{~mm}$. Untuk pencekaman benda kerja dihasilkan diameter dalam $11 \mathrm{~mm}$ sedang diameter luar $57.5 \mathrm{~mm}$ dengan ketebalan 30mm.

Pembuatan rangka dengan referensi yang sudah dibuat guna menghasilkan perkakas bantu yang dapat melakukan pemotongan yang berulang sehingga dihasilkan sebuah benda dengan bentuk yang sama untuk produk berikutnya. Rangka juga memberikan posisi bekerja yang sehat bagi operatornya dengan mempertimbangkan tinggi rangka tersebut yang disesuaikan dengan postur tubuh orang Indonesia. Ukuran rangka dapat di seperti gambar di bawah ini :

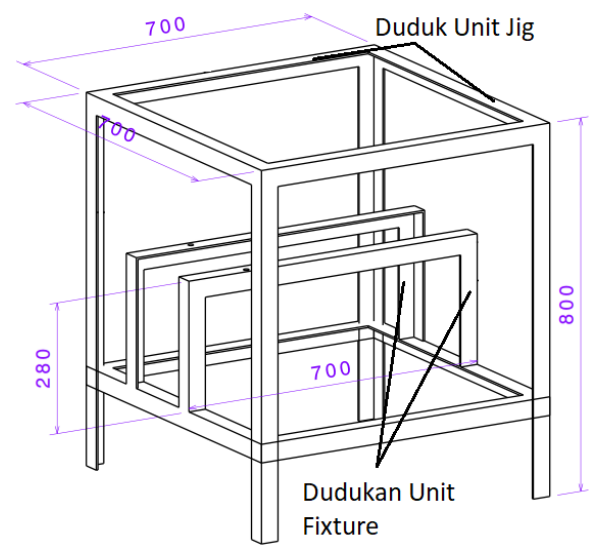

Gambar 9. Rangka Alat

\section{Pembuatan Perkakas Bantu}

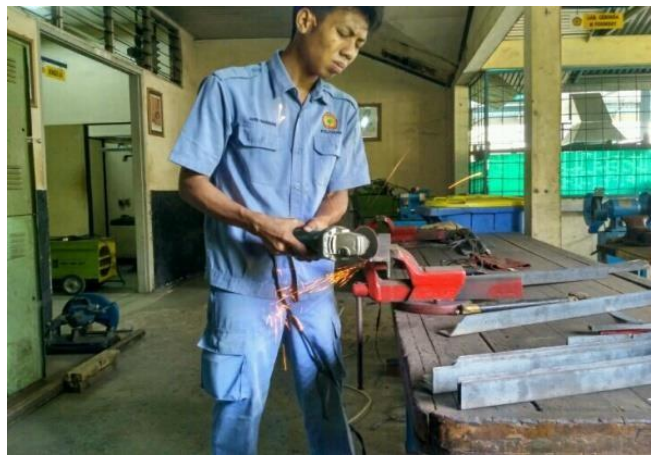

Gambar 10. Proses Pemotongan Komponen

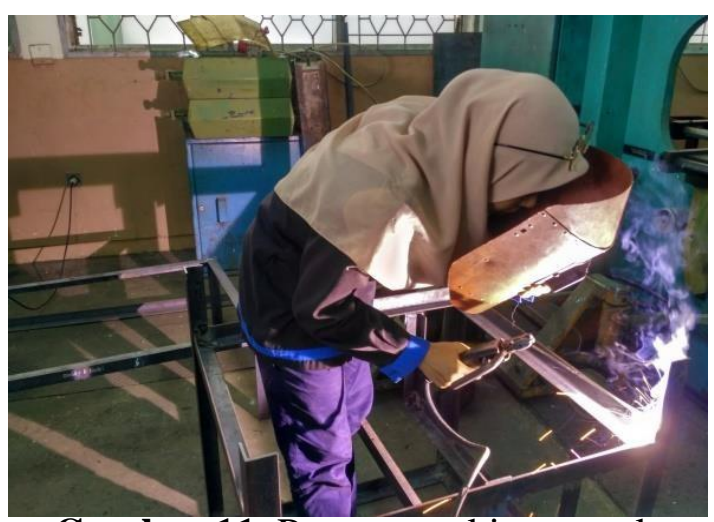

Gambar 11. Proses perakitan rangka

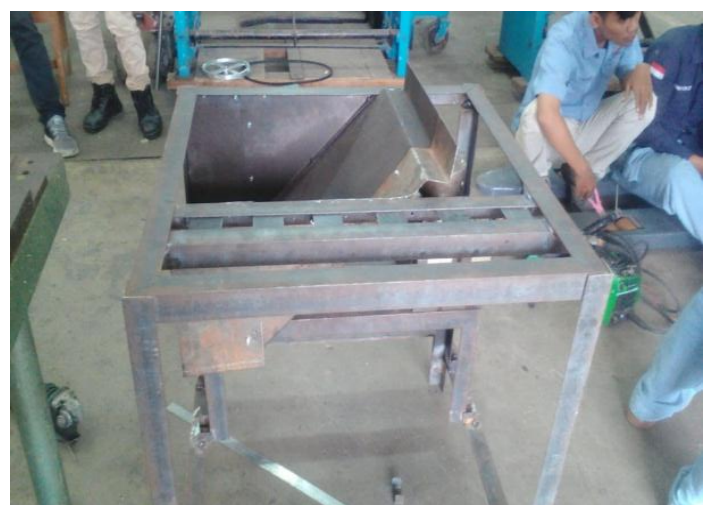

Gambar 12. Proses Assembling

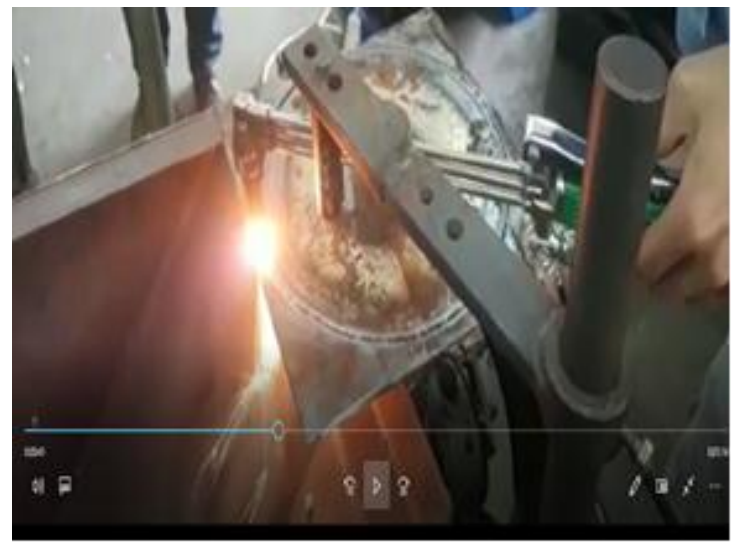

Gambar 13. Proses Pengujian

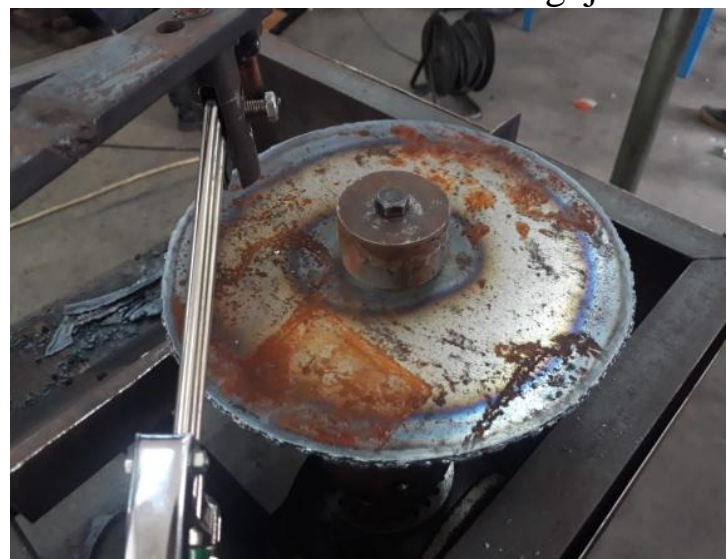

Gambar 14. Proses Pengujian 


\section{SIMPULAN}

Berdasarkan hasil penelitian, dapat diperoleh kesimpulan yaitu :

1. Satu mesin pembuat disk runner dengan ukuran runner berdiameter $300 \mathrm{~mm}$ yang dirancang serta dilakukan pembuatan.

2. Perkakas bantu jig dan fixture pembuat disk runner turbin mikrohidro ini berukuran $700 \mathrm{~mm} x$ $700 \mathrm{~mm}$ x $800 \mathrm{~mm}$ terdiri dari beberapa bagian utama yaitu : pemegang benda kerja, pemegang alat potong (torch), piring pembagi dan pengarah pemotongan lingkaran dan sudu.

3. Setelah mesin dibuat kemudian dilakukan pengujian dan telah menghasilkan produk bahan disk runner dengan ukuran diameter 300 mm serta lubang dudukan sudu.

Beberapa hal belum dapat dilakukan seperti hasil pemotongan dengan menggunakan torch dengan hasil potongan yang langsung dipakai.

\section{DAFTAR PUSTAKA}

Agnes R. Sulistyawati, Potensi Energi Mikrohidro di Sumbar capai 500 Megawatt,

http://regional.kompas.com/read/2009 102/12/09005371/ (Berita Kompas Online tanggal 12 September 2009)

Alex Arte dan Ueli Meier, SKAT, Seri Memanfaatkan Tenaga Air dalam Skala Kecil Buku 2, Pedoman Rekayasa Tenaga Air, Jakarta 1991.

C.A. Mockmore and Fred Merryfield, Engineering The Banki Water Turbine, Experiment Station Oregon State System Of Higher Education Oregon State College Corvallis Bulletin Series No. 25,1949.

Desai, V.R. and Aziz, N.M., An Experimental Investigation Of CrossFlow Turbine Efficiency, Journal of Fluids Engineering, Vol.116 (1944).
Dietzel,Fritz, Dakso Sriyono,Turbin Pompa dan Kompresor, Erlangga, Jakarta, 1993.

Efendi,Yunaldi, Perancangan Turbin Air Aliran Silang (Cross Flow Turbine), Tugas Akhir, Padang, 2009.

Khosrowpanah,S et al, Experimental Study Of Cross-Flow Turbine, Journal of Hydraulic Engineering,Vol.114,No.3 (1988).

Ferial, Provinsi Sumbar akan Menjadi Lumbung Energi Hijau, http://ebtke.esdm.go.id/670 (Berita Online Dirjen Energi Baru dan Terbarukan, Kementrian ESDM tanggal 13 September 2012)

Mocmore, C. A et al, The Banki Water Turbin, Engineering Experiment Station, Oregon State Colleg, Corvallis, Oregon, 1998. 